\title{
Article \\ High-Performance and Water Resistant PVA-Based Films Modified by Air Plasma Treatment
}

\author{
Xin Rao ${ }^{1,2}$, Qi Zhou ${ }^{1,2}$, Qin Wen ${ }^{1,2}$, Zhiqiang Ou ${ }^{1,2}$, Lingying Fu ${ }^{1,2}$, Yue Gong ${ }^{1,2}$, Xueyu Du ${ }^{1,2, *}$ \\ and Chunqing Huo ${ }^{3, *}$
}

1 Hainan Provincial Fine Chemical Engineering Research Center, Hainan University, Haikou 570228, China; 19085216210034@hainanu.edu.cn (X.R.); qduzhouqi@163.com (Q.Z.); wenqin_hg@hainanu.edu.cn (Q.W.); ouzhiqianghu@163.com (Z.O.); fulingyinghainan@163.com (L.F.); 13503529196@163.com (Y.G.)

2 Hainan Provincial Key Lab of Fine Chemistry, Hainan University, Haikou 570228, China

3 School of Materials Science and Engineering, Hainan University, Haikou 570228, China

* Correspondence: duxueyu@hainanu.edu.cn (X.D.); chunqinghuo@hainanu.edu.cn (C.H.)

Citation: Rao, X.; Zhou, Q.; Wen, Q.; Ou, Z.; Fu, L.; Gong, Y.; Du, X.; Huo, C. High-Performance and Water Resistant PVA-Based Films Modified by Air Plasma Treatment. Membranes 2022, 12, 249. https://doi.org/ $10.3390 /$ membranes12030249 Academic Editors: Hasan Sadeghifar and Lucian Lucia

Received: 30 January 2022

Accepted: 19 February 2022

Published: 22 February 2022

Publisher's Note: MDPI stays neutral with regard to jurisdictional claims in published maps and institutional affiliations.

Copyright: (C) 2022 by the authors. Licensee MDPI, Basel, Switzerland. This article is an open access article distributed under the terms and conditions of the Creative Commons Attribution (CC BY) license (https:// creativecommons.org/licenses/by/ $4.0 /)$.

\begin{abstract}
Plasma treatment is considered a straightforward, cost-effective, and environmentalfriendly technique for surface modification of film materials. In this study, air plasma treatment was applied for performance improvement of pure PVA, cellulose nanocrystal (CNC)/PVA, and CNC/oxalic acid (OA)/PVA films. Compared with the original performance of pure PVA, the mechanical properties and water resistance of air plasma treated films were greatly improved. Among them, the CNC/OA/PVA film treated by three minutes of air plasma irradiation exhibits the most remarkable performance in mechanical properties (tensile strength: $132.7 \mathrm{MPa}$; Young's modulus: $5379.9 \mathrm{MPa}$ ) and water resistance (degree of swelling: $47.5 \%$; solubility: $6.0 \%$ ). By means of various modern characterization methods, the wettability, surface chemical structure, surface roughness, and thermal stability of different films before and after air plasma treatment were further revealed. Based on the results obtained, the air plasma treatment only changed the surface chemical structure, surface roughness, and hydrophobicity, while keeping the inner structure of films intact.
\end{abstract}

Keywords: air plasma; PVA film; surface modification; water resistance; crosslinking

\section{Introduction}

To effectively alleviate the global environmental issue of plastic pollution, the development of biodegradable polymers has received tremendous attention in recent years. As a typical representative of semi-crystalline polymers, polyvinyl alcohol (PVA) is derived from the alcoholysis of polyvinyl acetate and its prevailing industrial applications are primarily ascribed to its remarkable properties in terms of biodegradability, biocompatibility, film-forming, solvent resistance, etc. [1]. Although PVA serves as a promising alternative to petroleum-based plastics, its application fields are still restricted by its poor water tolerance. The swelling phenomenon of PVA films inevitably occurs owing to the incorporation of water molecules and hydroxyl groups on the PVA molecular chains via strong hydrogen bonds, which consequently impairs the mechanical properties of the film products [2].

Therefore, proper structural modification is highly desired to improve the water resistance of PVA-based films. Traditionally, the modification of PVA films could be carried out by physical or chemical approaches [3]. Physical modification is featured as its relatively simplified preparation process and the establishment of hydrogen bonds between the reinforcing filler and PVA matrix normally accounts for the reason of its improved properties. To date, a large number of reinforcing fillers have been attempted to further improve the performance of PVA films, such as cellulose derivatives [4], modified starch [5], graphene [6], chitosan [7], etc. It is necessary to mention that although the reinforced network of hydrogen bonds does boost the mechanical properties to a large 
extent via effective stress transfer, it is still vulnerable if exposed to an aqueous or a high-humidity environment.

Chemical modification, on the other hand, could essentially resolve the poor water resistance by building up stable covalent bonds between fillers and the PVA matrix with the participation of a cross-linker. As a result, the major performance of PVA-based films regarding mechanical properties, water resistance, and thermal stability could be promoted. Traditional chemical cross-linkers had been reported as glyoxal [8], glutaraldehyde [9], diisocyanate [10], etc. However, these aldehydes are deemed as potential toxic additives existing in the ultimate film products if they could not be completely reacted. In the context of green and sustainable chemistry, green cross-linkers are emerging as competitive alternatives known as succinic acid [11], malic acid [12], tartaric acid [13] and other types of polyacids. Although polyacids themselves are regarded as environment-friendly reagents, their crosslinking processes commonly should be assisted by relatively harsh conditions (e.g., strong acids as catalysts, high crosslinking temperature, etc.)

Hence, it is still necessary to find a more environment-friendly modification technique for the preparation of water-tolerant PVA-based films. Recently, plasma treatment has received growing attention for its remarkable capacity in film surface modification. Compared with other film modification methods, plasma treatment has been highlighted by its low energy consumption, cost-effectiveness, and especially the fairly low output of byproducts or wastes [14]. As the fourth state of matter, plasma is generated from the ionization of specific gaseous molecules via dissociation of their intrinsic chemical bonds to form a collection of ions, electrons, free radicals, etc. $[15,16]$. Later, these highly reactive charged or neutral species would target on the surface of treated material during plasma irradiation and trigger scission and crosslinking of surface atoms and functional groups. Briefly, plasma treatment only functions on the surface of the material to cause physical etching and chemical reactions (e.g., crosslinking, grafting, etc.) without the assistance of additional initiators or reagents, while the inner characteristics of films still remains intact $[17,18]$.

Relevant research has therefore been carried out to promote the utilization of plasma treatment in the field of film modification. For instance, Dalei et al. applied low temperature argon plasma to modify the surface of cellulose/PVA biocomposites, which ultimately resulted in increased hydrophilicity and antimicrobial activity [19]. Yang et al. reported to prepare argon plasma treated PVA/starch blends with improved mechanical and thermal properties [20]. However, detailed changes in the surface structure and surface chemicalbonding state of PVA-based films after plasma treatment still need to be deepened and further elucidated.

In this study, a more cost-effective air plasma treatment was applied to disclose its potential benefits on integral performance enhancement of three different types of PVAbased films, namely pure PVA film, cellulose nanocrystal (CNC)/PVA blend film, and $\mathrm{CNC}$ /oxalic acid (OA)/PVA crosslinked film. After regulation of different plasma treatment durations, all test specimens had been analyzed in terms of mechanical properties, water resistance, and surface wettability. The variation of chemical bonding state and functional groups on the surface of the films before and after air plasma treatment had been emphatically revealed by XPS and FTIR. In addition, the surface morphology, characteristic X-ray patterns, and thermal stability of different PVA-based films had also been characterized by modern analytical techniques including AFM, XRD, and TGA.

\section{Materials and Methods}

\subsection{Materials}

Highly purified cellulose powder (99.5\%) was purchased from North Century Cellulose Material Co., Ltd. (Xuzhou, China). PVA (degree of polymerization: 1700; degree of alcoholysis: $98-99 \%(\mathrm{~mol} / \mathrm{mol})$ ) was purchased from Aladdin Co., Ltd. (Shanghai, China). Oxalic acid (99.5 wt\%) and ethanol were supplied by Macklin Co., Ltd. (Shanghai, China). Besides, sulfuric acid (95.0-98.0 wt\%) was provided by Xilong Science Co., Ltd. 
(Guangzhou, China). All chemicals used were of analytical pure grade and deionized water was used for all experiments.

\subsection{Preparation of Cellulose Nanocrystals (CNCs)}

$10 \mathrm{~mL}$ of $64 \mathrm{wt} \%$ aqueous sulfuric acid solution and $1 \mathrm{~g}$ of cellulose fine powder were added into a $50 \mathrm{~mL}$ conical beaker. The acid hydrolysis reaction was performed under $50{ }^{\circ} \mathrm{C}$ for $1 \mathrm{~h}$ with magnetic stirring. Subsequently, the reaction was quenched by the addition of excess deionized water. The resultant residue obtained after centrifugation was further dialyzed for three days. Later, the purified suspension was transferred to a double-layer glass beaker and sonicated under $1200 \mathrm{~W}$ for $20 \mathrm{~min}$ by a JY98-IIIL ultrasonic cell crusher (Zhejiang Declair Instruments Co., Ltd., Hangzhou, China) at $4{ }^{\circ} \mathrm{C}$. The $\mathrm{CNC}$ suspension was then acquired and stored in a refrigerator at $4{ }^{\circ} \mathrm{C}$ for future use.

\subsection{Preparation of Pure PVA Film, CNC/PVA Blend Films, and CNC/OA/PVA Cross-Linked Films}

Pure PVA film was prepared by dissolving $23.0 \mathrm{~g}$ of PVA into $100 \mathrm{~mL}$ deionized water at $100{ }^{\circ} \mathrm{C}$. After that, the solution was cooled at room temperature and set still for $3 \mathrm{~h}$ to expel air bubbles. The film was then fabricated by using a KW-4A benchtop spin coater (Institute of Microelectronics, Chinese Academy of Sciences, Beijing, China). In short, the PVA solution was gently added onto a clean square polyethylene substrate $(15 \mathrm{~cm} \times 15 \mathrm{~cm})$ with a rotating speed at $400 \mathrm{rpm}$ for $36 \mathrm{~s}$. The spin-coated substrate was then dried in an oven at $50{ }^{\circ} \mathrm{C}$ for $24 \mathrm{~h}$. Subsequently, the pure PVA film was peeled off from the substrate and kept in a sealed plastic bag for future use.

$\mathrm{CNC}$ was served as a reinforcing filler in preparation of $\mathrm{CNC} / \mathrm{PVA}$ blend film and its dry weight was formulated as 3\% with respect to the dry weight of PVA. Briefly, a prescribed amount of CNC suspension was pre-dispersed in $100 \mathrm{~mL}$ deionized water under sonication. Later, $23.0 \mathrm{~g}$ of PVA was charged into the suspension and the whole system was treated at $100{ }^{\circ} \mathrm{C}$ with magnetic stirring until PVA particles were completely dissolved. The suspension was cooled at room temperature and set still for $3 \mathrm{~h}$ to remove air bubbles. The subsequent steps were the same as for the preparation of pure PVA film.

The preparation process of CNC/OA/PVA cross-linked film was briefly described as follows. First, a certain amount of CNC suspension was pre-dispersed into $100 \mathrm{~mL}$ deionized water with the assistance of sonication. The dry weight of $\mathrm{CNC}$ was controlled as $3 \%$ based on the dry weight of PVA. Later, $6.9 \mathrm{~g}$ of OA and $23.0 \mathrm{~g}$ of PVA were supplemented into the above suspension and the entire system was heated up to $100{ }^{\circ} \mathrm{C}$ with magnetic stirring until the PVA was completely dissolved. The resultant mixture was cooled at room temperature and set still for $3 \mathrm{~h}$ to remove air bubbles. The subsequent spin coating procedure was the same as described for the preparation of pure PVA film. Finally, the resultant product was further treated at $120^{\circ} \mathrm{C}$ for $0.5 \mathrm{~h}$ to obtain CNC/OA/PVA crosslinked films. The thickness of all film specimens were controlled at $0.1 \mathrm{~mm}$.

\subsection{Air Plasma Treatment}

The air plasma treatment of PVA-based films were performed by using a SPA-2800 air plasma cleaner (Guangdong Dainty Intelligent Technology Co., Ltd., Dongguan, China). The main operation parameters are described as follows: voltage (220 V), power $(580-620 \mathrm{~W})$, air pressure (0.1-0.3 MPa). Each type of PVA-based films was treated by three different time intervals (i.e., $1 \mathrm{~min}, 3 \mathrm{~min}$, and $5 \mathrm{~min}$ ). The pure PVA films exposed to $1 \mathrm{~min}, 3 \mathrm{~min}$, and 5 min of air plasma were labeled as PPVA-1, PPVA-3, and PPVA-5, respectively. Likewise, the CNC/PVA blend films treated by $1 \mathrm{~min}, 3 \mathrm{~min}$, and $5 \mathrm{~min}$ of air plasma were labeled as CNC/PPVA-1, CNC/PPVA-3, and CNC/PPVA-5, respectively. A similar labeling rule was also applied to air plasma-treated CNC/OA/PVA films. 


\subsection{Characterization}

\subsubsection{X-ray Photoelectron Spectroscopy}

The surface chemistry and elemental composition of different films were analyzed by a 250Xi X-ray photoelectron spectrometer (Thermo Fisher Scientific, Waltham, MA, USA), equipped with a monochromated Al-K $\alpha$ source $(1486.6 \mathrm{eV})$. The spectra were recorded in a background pressure of $1 \times 10^{-10}$ mbar. Besides, the pass energy was set as $100 \mathrm{eV}$ for survey spectra (a step of $1 \mathrm{eV}$ ) and $20 \mathrm{eV}$ for high resolution spectra (a step of $0.1 \mathrm{eV}$ ). All XPS spectra acquired were further processed by Avantage software.

\subsubsection{Fourier Transform Infrared Spectroscopy (FTIR)}

FTIR was carried out by a Bruker Nicolet iS50 spectrophotometer (Karlsruhe, Germany) with an attenuated total reflectance (ATR) attachment. The spectra were recorded in the range from $4000 \mathrm{~cm}^{-1}$ to $500 \mathrm{~cm}^{-1}$ at a resolution of $4 \mathrm{~cm}^{-1}$.

\subsubsection{Atomic Force Microscopy (AFM)}

The surface morphology of films was investigated by using a Dimension Icon atomic force microscope (Bruker, Karlsruhe, Germany). The root mean square roughness (Rq) was measured by using NanoScope Analysis software.

\subsubsection{Water Resistance}

The water resistance of different films was evaluated including their individual degree of swelling and solubility. All samples were pre-cut into the squares of $2.0 \mathrm{~cm} \times 2.0 \mathrm{~cm}$ and immersed in deionized water at room temperature for $24 \mathrm{~h}$. The samples were then removed and immediately dried with dust-free tissues to remove surface moisture. Later, the swelled samples were dried in an oven at $50{ }^{\circ} \mathrm{C}$ until the weight was constant. The original dry weights of films and the weights before and after oven drying for calculating the degree of swelling and solubility were recorded according to Equations (1) and (2) as follows:

$$
\begin{gathered}
\text { Degree of swelling }=\frac{m_{b}-m_{a}}{m_{a}} \times 100 \% \\
\text { Solubility }=\frac{m_{a}-m_{c}}{m_{a}} \times 100 \%
\end{gathered}
$$

where $m_{a}$ is the original dry weight of test film, $g ; m_{b}$ is the weight of the swelled film after removing its surface moisture, $g$; and $m_{c}$ is the dry weight of the film re-dried after soaking in deionized water for $24 \mathrm{~h}$.

\subsubsection{Mechanical Properties}

The tensile strength and Young's modulus of different films were determined by an Instron 3343 long travel extensometer, using a load of $1 \mathrm{KN}$ at a strain rate of $10 \mathrm{~mm} / \mathrm{min}$. The sample dimension was sized by $1 \mathrm{~cm}$ (width) $\times 10 \mathrm{~cm}$ (length) and a minimum of five test runs were carried out for each specimen prior to the calculation of average value and deviation. All specimens were tested at an ambient temperature $\left(25^{\circ} \mathrm{C}\right)$ and $80 \%$ relative humidity.

\subsubsection{Water Contact Angle}

The water contact angles of different films were measured by an SL200KB optical contact angle/interface tensiometer (Kino Industry Co. Ltd., Boston, MA, USA). The images of water droplets were taken $3 \mathrm{~s}$ after placing the droplets, and all the measurements were performed at $25^{\circ} \mathrm{C}$.

\subsubsection{Thermogravimetric Analysis}

The thermal stability of different films were determined by a NETZSCH STA 449 F5 thermogravimetric analyzer (NETZSCH, Selb, Germany). Each sample was heated from 
$30{ }^{\circ} \mathrm{C}$ to $600{ }^{\circ} \mathrm{C}$ at a rate of $10{ }^{\circ} \mathrm{C} / \mathrm{min}$ and the flow rate of carrier gas $\left(\mathrm{N}_{2}\right)$ was set as $20 \mathrm{~mL} / \mathrm{min}$.

\subsubsection{X-ray Diffraction Analysis}

The crystal characteristics of different films was investigated by a Smart Lab X-ray diffractometer (Rigaku, Tokyo, Japan). Each measurement was scanned from $5^{\circ}$ to $30^{\circ}$ at a rate of $5^{\circ} / \mathrm{min}$.

\section{Results and Discussion}

\subsection{Mechanical Properties}

Film materials are subject to various external forces during practical use. If the major mechanical properties fail to meet the basic requirements, its application fields will be largely restricted. Tensile strength and Young's modulus are two key performance indexes for evaluating the mechanical properties of films [21], and their corresponding values of different PVA-based films are shown in Figure 1.
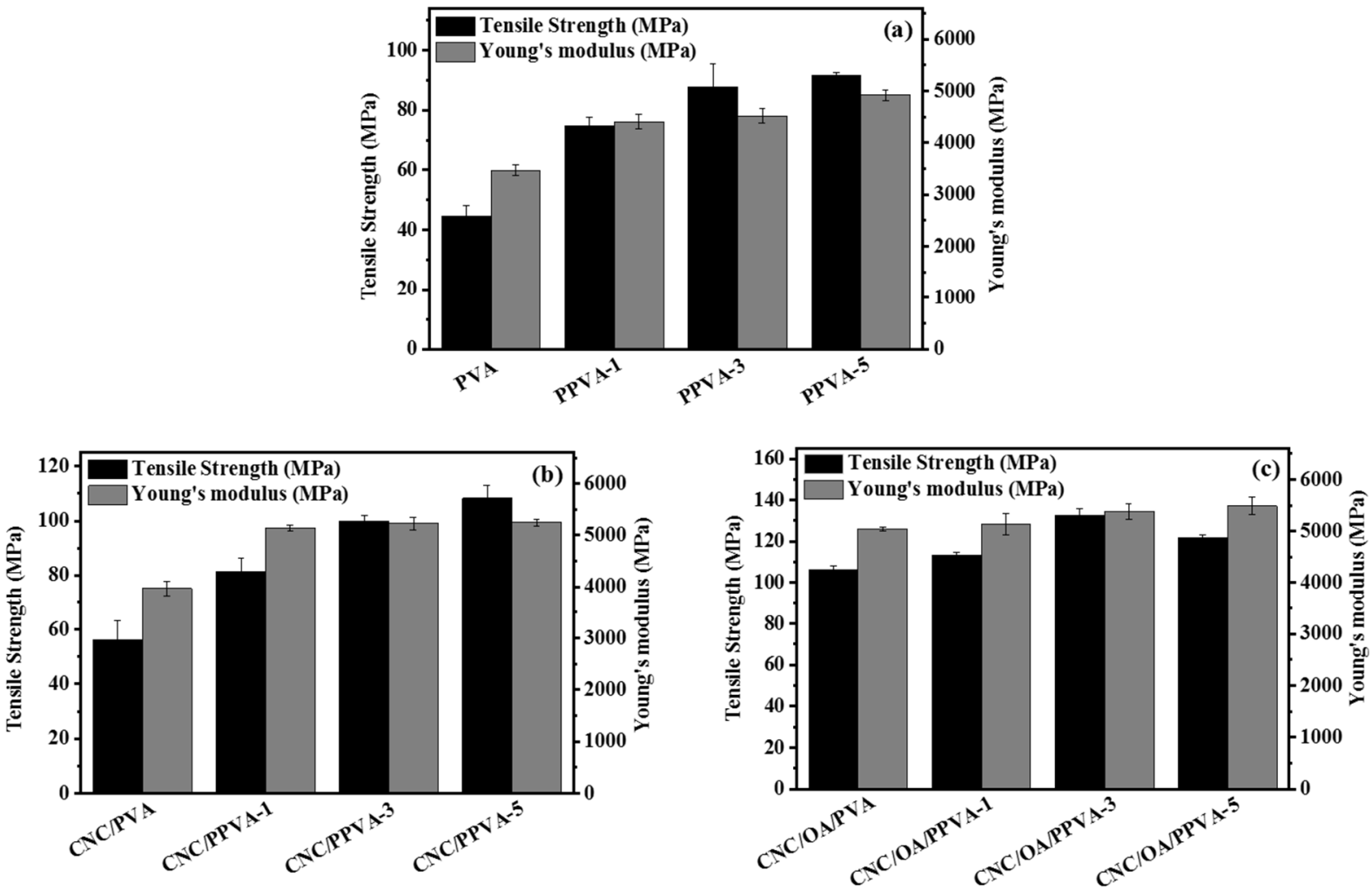

Figure 1. Tensile strength and Young's modulus of different films without or with air plasma treatment. (a) PVA and its air plasma-treated films (PPVA-1, PPVA-3, and PPVA- 5 are referring to the PVA films exposed to air plasma irradiation by $1 \mathrm{~min}, 3 \mathrm{~min}$, and $5 \mathrm{~min}$, respectively.); (b) CNC/PVA and its air plasma-treated films (CNC/PPVA-1, CNC/PPVA-3, and CNC/PPVA-5 are referring to the CNC/PVA films exposed to air plasma irradiation by $1 \mathrm{~min}, 3 \mathrm{~min}$, and $5 \mathrm{~min}$, respectively.); (c) $\mathrm{CNC} / \mathrm{OA} / \mathrm{PVA}$ and its air plasma-treated films (CNC/OA/PPVA-1, CNC/OA/PPVA-3, and $\mathrm{CNC} / \mathrm{OA} / \mathrm{PPVA}-5$ are referring to the $\mathrm{CNC} / \mathrm{OA} / \mathrm{PVA}$ films exposed to air plasma irradiation by $1 \mathrm{~min}, 3 \mathrm{~min}$, and $5 \mathrm{~min}$, respectively).

For PVA and CNC/PVA films, the plasma treatment favors the enhancement of both tensile strength and Young's modulus. Their respective values continuously increase following the increment of plasma irradiation time. The maximum values were achieved for PPVA-5 (tensile strength: 91.6 MPa; Young's modulus: $4921 \mathrm{MPa}$ ) and CNC/PPVA-5 (tensile strength: $108.3 \mathrm{MPa}$; Young's modulus: $5243.8 \mathrm{MPa}$ ) when 5 min of plasma irradiation 
was applied (Figure 1a,b). During plasma irradiation, the $\mathrm{C}-\mathrm{C}$ and $\mathrm{C}-\mathrm{H}$ bonds present on film surface are disrupted by reactive ionic species. As a result, the generated radicals can react with surface radicals or participate in surface cross-linking reactions, resulting in a remarkable increase in mechanical properties [22]. In addition, the moisture content of the specimen was further eliminated during plasma irradiation, which rendered the PVA molecular chains more tightly bound with each other via inter and intramolecular hydrogen bonds [23]. More carbonyl groups could be formed during plasma irradiation, also contributing to a more advanced network of hydrogen bonds. This may greatly improve the structural integrity of the film, enhance interfacial interactions between/among film components, and favor the stress transfer [24].

For CNC/OA/PVA and its air plasma treated films, the variation trend of Young's modulus still remains consistent, as with the cases mentioned above. However, after reaching the maximum value of tensile strength (132.7 MPa) as in the case of CNC/OA/PPVA-3, its value started to decline with further extension of plasma irradiation time up to $5 \mathrm{~min}$ (Figure 1c). This may be due to the severe physical etching on the film surface caused by long-term plasma bombardment, which destroyed the original densely cross-linked surface structure of the film [25].

\subsection{Water Resistance}

The improvement of water resistance for different films after air plasma treatment is demonstrated in Figure 2. It is noteworthy that both the degree of swelling and solubility of plasma-treated PVA and plasma-treated CNC/PVA films exhibit a continuous reduction trend when plasma irradiation time was extended from $1 \mathrm{~min}$ to $5 \mathrm{~min}$. The minimum values of degree of swelling (185.6\%) and solubility (7.4\%) for CNC/PPVA-5 are even lower than those (degree of swelling: 205.8\%; solubility: 8.1\%) for PPVA-5 (Figure 2a,b). During the process of plasma treatment, the oxygen radicals take part in the formation of a crosslinking network on the film surface, which effectively prevents the invasion of water molecules [23]. Also, these reactive oxygen radicals favor the oxidation of hydroxyl groups on the film surface to carbonyl groups, which facilitates the formation of hydrogen bonds [26].

Ascribed to the inherent ester bond cross-linkages, the water resistance of $\mathrm{CNC} / \mathrm{OA} / \mathrm{PVA}$ film is more superior to that of CNC/PPVA- 5 film. The degree of swelling and solubility of $\mathrm{CNC} / \mathrm{OA} / \mathrm{PVA}$ film are low up to $53.5 \%$ and $5.7 \%$, respectively. It is noticeable that there is no evident change in solubility for $\mathrm{CNC} / \mathrm{OA} / \mathrm{PVA}$ films treated by different time intervals of air plasma. However, the degree of swelling rebounds gently to $51.4 \%$ (for CNC/OA/PPVA-5) after reaching its minimum value of $47.5 \%$ (for CNC/OA/PPVA-3) (Figure 2c). Generally, the plasma treatment did improve the water tolerance of $\mathrm{CNC} / \mathrm{OA} / \mathrm{PVA}$ film but to a minor extent. The highly reactive charged and neutral particles generated by plasma irradiation can readily oxidize hydroxyl groups and contribute to a more reinforced crosslinking network on the film surface, but the number of free hydroxyl groups in CNC/OA/PVA film is fairly limited, the majority of which had already been consumed for the establishment of ester bond cross-linkages. Moreover, those plasma particles mentioned above may still be inefficient to interrupt the inherent ester bond cross-linkages within a short time of plasma treatment. However, if the treatment time had lasted for $5 \mathrm{~min}$ (for CNC/OA/PPVA-5), the accumulated plasma etching could cleave the original ester bonds to some extent and eventually result in an increment of the degree of swelling.

\subsection{Surface Wettability}

The water contact angle is considered to be an important index to quickly assess the hydrophilicity or hydrophobicity of films. The higher the contact angle is, the more hydrophobic surface the film possesses. It is clear that the contact angle of the film with plasma treatment is higher than that of the untreated film (Figure 3). Furthermore, when the time of treatment is prolonged from $1 \mathrm{~min}$ to $3 \mathrm{~min}$, the surface of test films turned out to be more hydrophobic, reflected by their increasing contact angles in different degrees. 
For each series of films, their corresponding highest contact angles could all have been acquired when 3 min of treatment time was applied. As mentioned before, the plasma treatment promotes the oxidation of hydroxyl groups into carbonyl groups that are more prone to form new hydrogen bonds. Therefore, the film surface turns out to be more hydrophobic, followed by a reduced amount of hydrophilic hydroxyl groups [26]. However, this increasing trend of surface hydrophobicity could not be well maintained if the time of plasma irradiation continues to proceed. When $5 \mathrm{~min}$ of irradiation was applied, the contact angles of all test films dropped to different extents. The contact angle of CNC/OA/PPVA-5 film $\left(61.5^{\circ}\right)$ is even lower than $\mathrm{CNC} / \mathrm{OA} / \mathrm{PVA}$ film $\left(65.8^{\circ}\right)$ (Figure 3). This result may be attributed to the excessive etching by air plasma, which destroys the hydrophobic structure by releasing more polar groups present on the film surface.
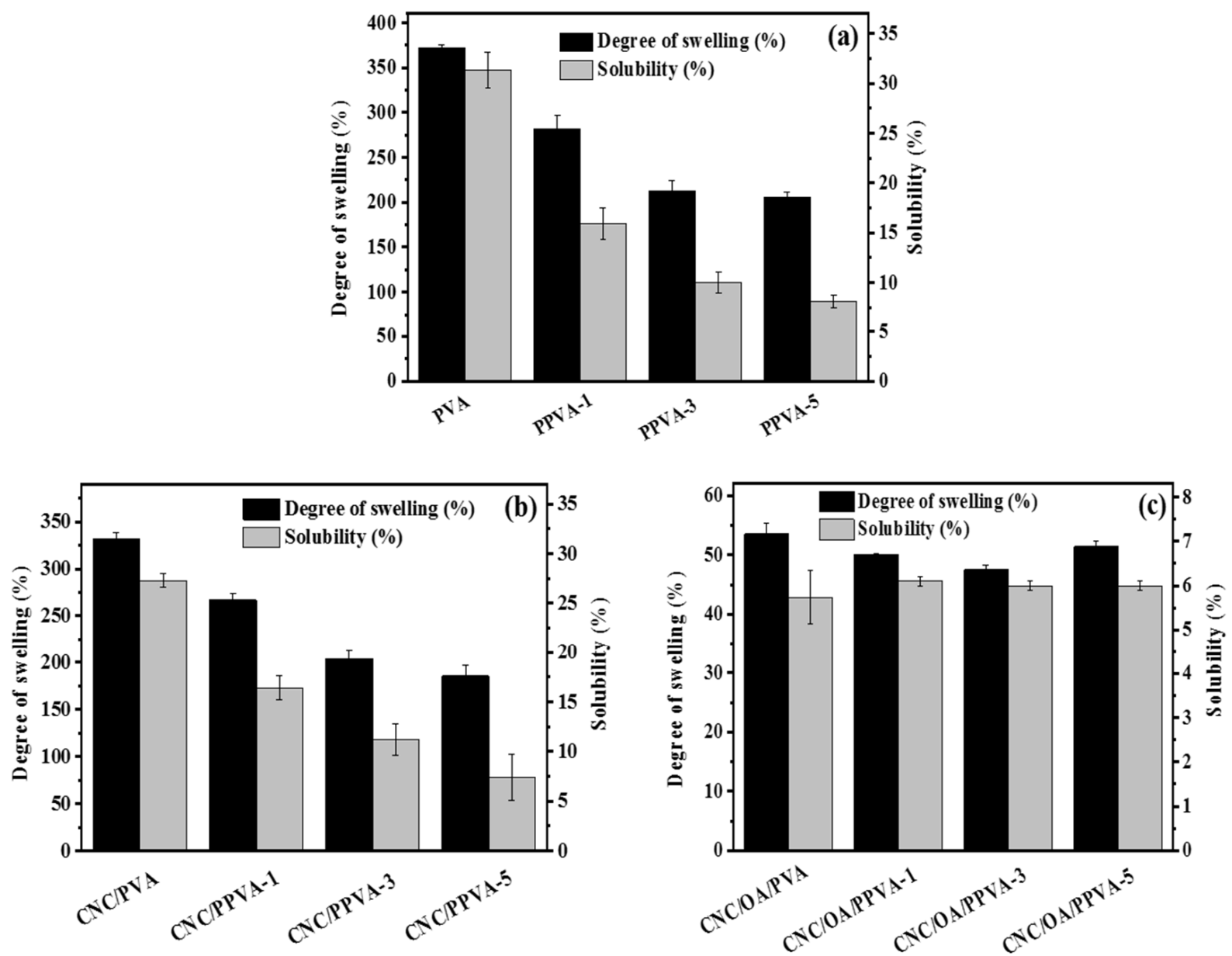

Figure 2. The degree of swelling and solubility of different films without or with air plasma treatment. (a) PVA and its air plasma-treated films; (b) CNC/PVA and its air plasma-treated films; (c) CNC/OA/PVA and its air plasma-treated films.

\subsection{Surface Chemical Study}

To better elucidate the elemental composition and chemical changes of plasma modified film surfaces, XPS was applied and the relevant results are summarized in Table 1. According to the relative contents of $\mathrm{C}$ and $\mathrm{O}$ atoms from the film surface, the $\mathrm{C} / \mathrm{O}$ ratios of plasma modified films are calculated and the results are conspicuously lower than those of untreated films. This implies the presence of more oxygen-containing groups existing on the film surface. Here, high resolution XPS spectra of C1s and O1s were recorded to release more information regarding chemical bonding relationships (Figures 4 and S1). As shown in Figure 4, four deconvoluted peaks are observed for all three types of untreated films. Their respective binding energy was detected as $284.8 \mathrm{eV}, 286.2 \mathrm{eV}, 288.2 \mathrm{eV}$, and 
$289.1 \mathrm{eV}$, corresponding to $\mathrm{C}-\mathrm{C}$ [27], $\mathrm{C}-\mathrm{O}[28], \mathrm{C}=\mathrm{O}$, and $\mathrm{O}-\mathrm{C}=\mathrm{O}$ [29], respectively. In addition, the O1s spectra of all six films were also resolved and fitted in the Supplementary Materials (Figure S1). It is interesting to note that there is only one peak referring to $\mathrm{C}-\mathrm{O}(531.4 \mathrm{eV})$ [30], while two more deconvoluted peaks emerged at $530.2 \mathrm{eV}(\mathrm{C}=\mathrm{O})$ and $533.8 \mathrm{eV}(\mathrm{O}-\mathrm{C}=\mathrm{O})$ in the spectrum of PPVA-3-O1s [31]. This directly verifies the presence of newly formed carbonyl and carboxylic groups after plasma treatment. It is necessary to point out that those groups $(\mathrm{O}-\mathrm{C}=\mathrm{O}$ and $\mathrm{C}=\mathrm{O})$ are inherent in untreated $\mathrm{CNC} / \mathrm{PVA}$ and $\mathrm{CNC} / \mathrm{OA} / \mathrm{PVA}$ films, which explains the existence of their corresponding signals in the spectra of CNC/PVA-O1s and CNC/OA/PVA-O1s. After plasma treatment, however, the intensities of these peaks had been evidently enhanced.

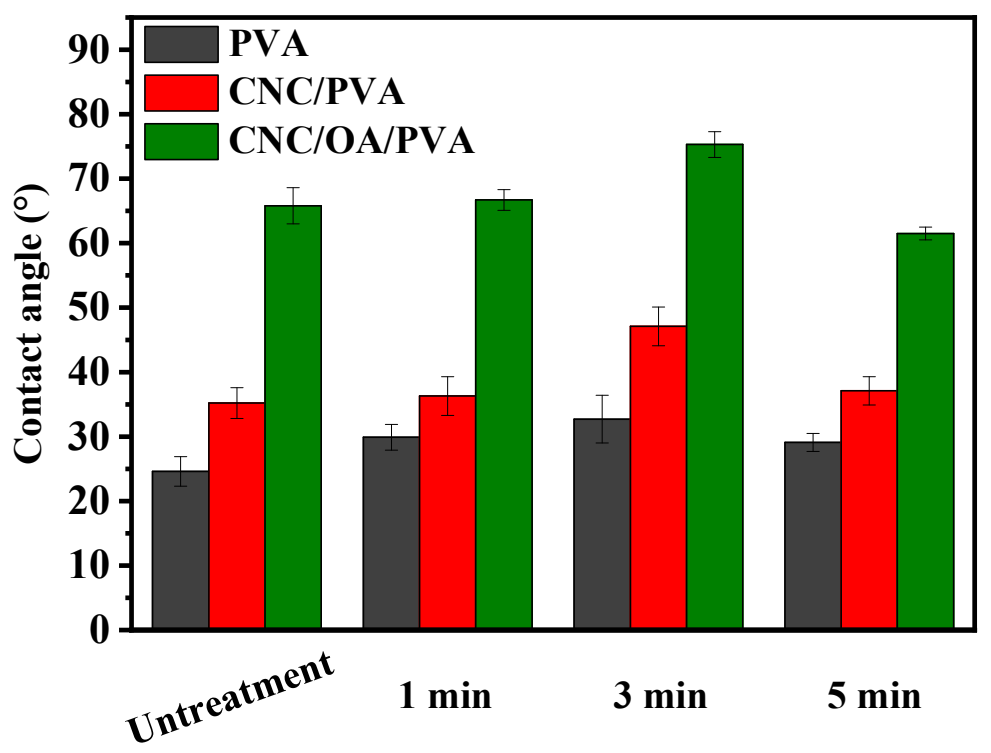

Figure 3. Contact angles of different films treated without or with air plasma.

Table 1. Atomic composition and $\mathrm{C} / \mathrm{O}$ ratios of different films without or with air plasma treatment.

\begin{tabular}{lccc}
\hline Sample & C & O & C/O \\
\hline PVA & 79.5 & 20.5 & 3.9 \\
PPVA-3 & 74.0 & 26.0 & 2.8 \\
CNC/PVA & 72.3 & 27.7 & 2.6 \\
CNC/PPVA-3 & 67.5 & 32.5 & 2.1 \\
CNC/OA/PVA & 77.0 & 23.0 & 3.4 \\
CNC/OA/PPVA-3 & 71.3 & 28.7 & 2.5 \\
\hline
\end{tabular}

The relative contents of different chemical bonding states are listed in Table 2. According to the spectra of $\mathrm{C} 1 \mathrm{~s}$, the relative contents of $\mathrm{C}-\mathrm{C}$ bonds of plasma modified films are lower than those of their respective untreated films. This result is well supported by an earlier documented study that found that the original $\mathrm{C}-\mathrm{H}$ and $\mathrm{C}-\mathrm{C}$ bonds in PVA could be oxidized to $\mathrm{C}-\mathrm{O}, \mathrm{C}=\mathrm{O}$, and $\mathrm{O}-\mathrm{C}=\mathrm{O}$ groups after air plasma treatment [32]. In other words, the increasing relative contents of oxygen-containing groups results in the decrement of the relative content of $\mathrm{C}-\mathrm{C}$ bonds. Besides, the effects of air plasma etching, caused by reactive oxygen radicals, may also destroy the surface chemical linkages e.g., $\mathrm{C}-\mathrm{C}$ bonds and thus brings down its relative contents [18]. According to the spectra of O1s, the relative contents of $\mathrm{O}-\mathrm{C}=\mathrm{O}$ and $\mathrm{C}=\mathrm{O}$ also increase as a consequence of air plasma treatment. A possible reaction mechanism for air plasma treatment of CNC/OA/PVA is proposed in Figure S2. 

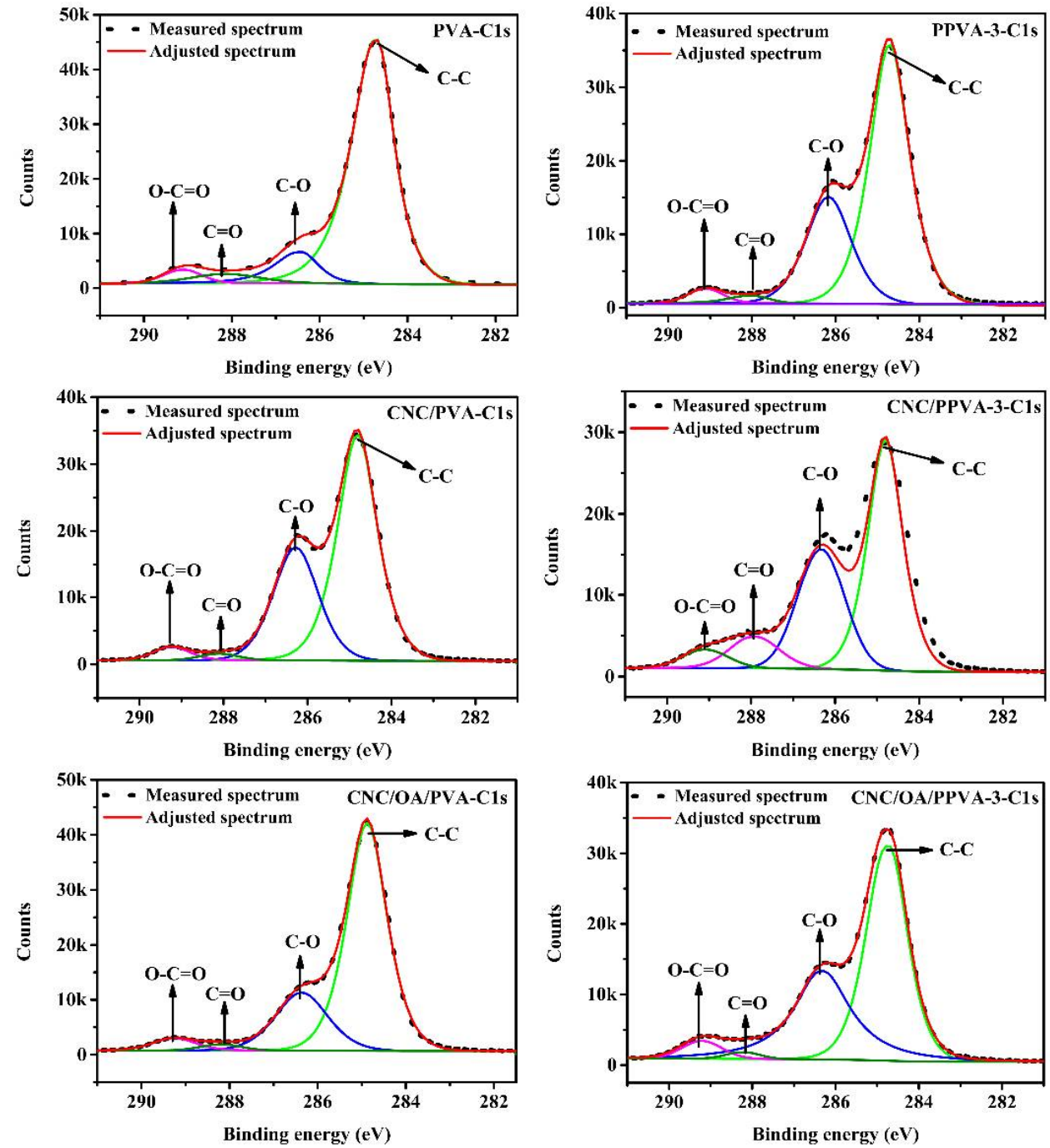

Figure 4. High resolution XPS spectra of C1s of different films without and with air plasma treatment.

Table 2. Relative contents of different chemical bonding relationships in XPS-C1s and -O1s spectra.

\begin{tabular}{|c|c|c|c|c|c|c|c|}
\hline \multirow[t]{3}{*}{ Samples } & \multicolumn{7}{|c|}{ Relative Contents (\%) } \\
\hline & \multicolumn{4}{|c|}{ C1s } & \multicolumn{3}{|c|}{ O1s } \\
\hline & $\mathrm{C}-\mathrm{C}$ & $\mathrm{C}-\mathrm{O}$ & $\mathrm{O}-\mathrm{C}=\mathrm{O}$ & $\mathrm{C}=\mathrm{O}$ & $\mathrm{C}-\mathrm{O}$ & $\mathrm{O}-\mathrm{C}=\mathrm{O}$ & $\mathrm{C}=\mathrm{O}$ \\
\hline PVA & 81.4 & 10.6 & 3.6 & 4.4 & 100.0 & - & - \\
\hline PPVA-3 & 65.1 & 25.5 & 4.3 & 5.1 & 83.6 & 11.8 & 4.6 \\
\hline $\mathrm{CNC} / \mathrm{PVA}$ & 61.8 & 33.4 & 3.2 & 1.6 & 85.5 & 10.1 & 4.4 \\
\hline CNC/PPVA-3 & 51.9 & 33.7 & 9.4 & 5.1 & 64.5 & 19.6 & 15.9 \\
\hline CNC/OA/PVA & 71.3 & 22.8 & 4.1 & 1.8 & 81.8 & 15.0 & 3.2 \\
\hline CNC/OA/PPVA-3 & 56.5 & 34.8 & 5.6 & 3.1 & 71.6 & 20.8 & 7.5 \\
\hline
\end{tabular}

\subsection{Surface Functional Groups}

The FTIR spectra of different films before and after air plasma treatment are illustrated in Figure 5. In contrast to the spectra of untreated films, there are no new adsorption bands observed in the spectra of plasma treated films, indicating the air plasma treatment did not substantially change the bulk structure of the PVA-based films. Despite this, the plasma treatment did change the intensities of some major adsorption peaks. For instance, the intensities of adsorption bands around $3279 \mathrm{~cm}^{-1}$, referring to $\mathrm{O}-\mathrm{H}$ stretching vibration, are significantly weakened for plasma treated films, which is due to the oxidation of hydroxyl 
groups to carbonyl and carboxylic groups during plasma treatment [24]. The reduction of hydroxyl groups is also evidenced by the decreased adsorption peak of $\mathrm{O}-\mathrm{H}$ bending vibration at $1320 \mathrm{~cm}^{-1}$. Besides, the cleavage of $\mathrm{C}-\mathrm{H}$ and $\mathrm{C}=\mathrm{C}$ bonds during plasma treatment could also be reflected by the decreased intensities of $\mathrm{C}-\mathrm{H}\left(2909 \mathrm{~cm}^{-1}\right)$ and $\mathrm{C}=\mathrm{C}$ $\left(1642 \mathrm{~cm}^{-1}\right)$ stretching vibration peaks. These types of cleavage also promote the formation of more reaction sites on the film surface [33].

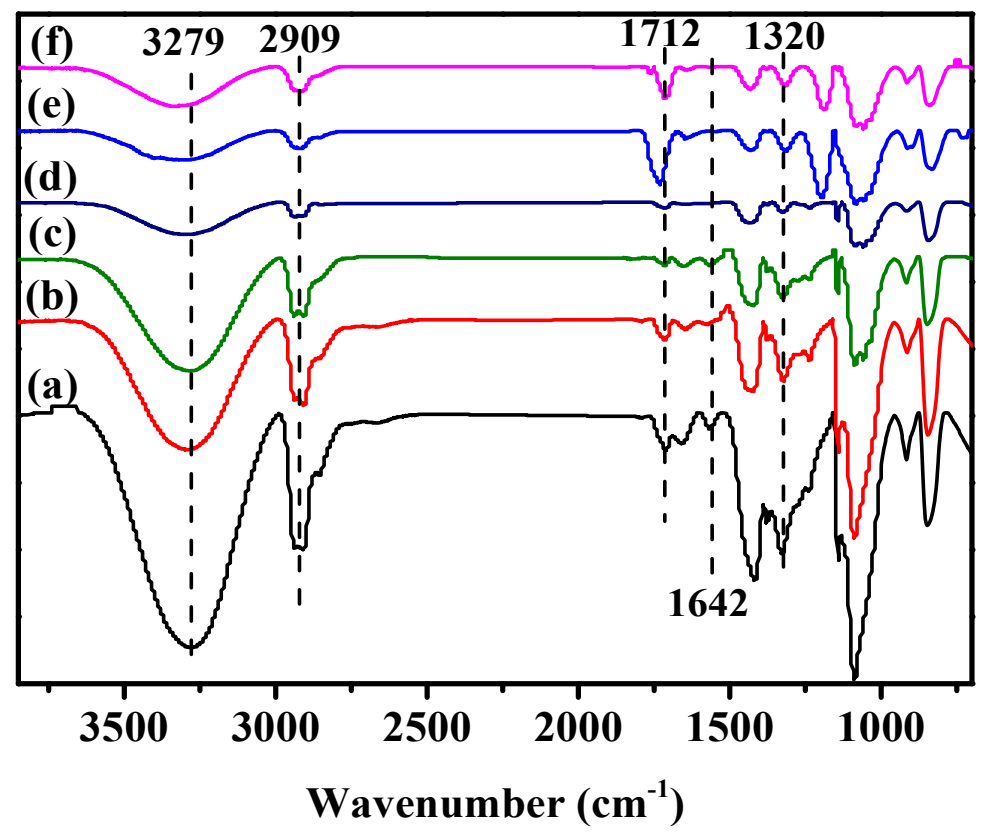

Figure 5. FTIR spectra of different films before and after air plasma treatment. (a) PVA film; (b) PPVA-3 film; (c) CNC/PVA film; (d) CNC/PPVA-3 film; (e) CNC/OA/PVA film; (f) CNC/OA/PPVA-3 film.

\subsection{Surface Morphology}

The occurrence of surface etching is inevitable during plasma treatment due to the impact of high-energy and highly reactive particles targeted onto the film surface. Detailed structural information regarding surface morphology and roughness of different films before and after plasma treatment were characterized by atomic force microscopy (AFM) (Figure 6). As demonstrated in Figure 6, the surface of PVA, CNC/PVA, and CNC/OA/PVA films is relatively smooth and their corresponding surface roughness was analyzed to be $4.5 \mathrm{~nm}, 17.4 \mathrm{~nm}$, and $28.9 \mathrm{~nm}$, respectively. After $3 \mathrm{~min}$ of plasma treatment, the surface of modified films including PPVA-3, CNC/PPVA-3, and CNC/OA/PPVA-3 turned out to be more coarse and irregular, and more nano-structured columnar bumps could also be observed. Their corresponding surface roughness increased to $14.9 \mathrm{~nm}, 43.3 \mathrm{~nm}$, and $50.0 \mathrm{~nm}$, respectively. This significant increase in surface roughness for all treated films is attributed to the physical etching/ion bombardment by excited particles during plasma treatment $[33,34]$. According to related studies, increased surface roughness may also lead to high surface hydrophobicity [35], which is confirmed by the higher contact angles of three plasma treated films (Figure 3). And the surface roughness is greatly influenced by the power and time of plasma treatment [36].

\subsection{Crystal Structure}

The X-ray diffraction patterns of different films are shown in Figure 7. Characteristic diffraction signals of PVA are detected at $19.8^{\circ}$ and $22.8^{\circ}$ for all test films, which are originating to the 101 and 200 planes of semi-crystalline PVA, respectively [37,38]. Notably, there is no obvious difference in diffraction patterns of different films, indicating that air plasma treatment does not vary the bulk crystal structure of PVA, which is in line with the findings of a recent study [18]. Nevertheless, the air plasma irradiation did increase the 
signal intensities at $19.8^{\circ}$, which is probably attributed to the minor structural changes of PVA molecular chains by plasma irradiation [16].

(a) $\mathrm{Rq}=4.5 \mathrm{~nm}$

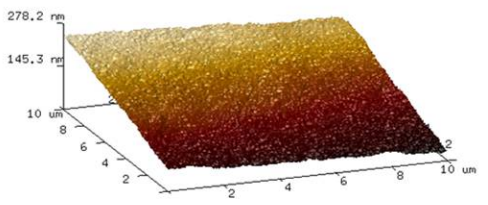

(c) $\mathrm{Rq}=17.4 \mathrm{~nm}$

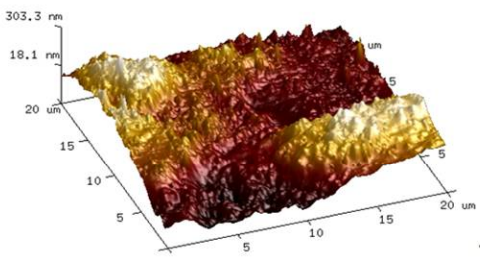

(e) $\mathrm{Rq}=28.9 \mathrm{~nm}$

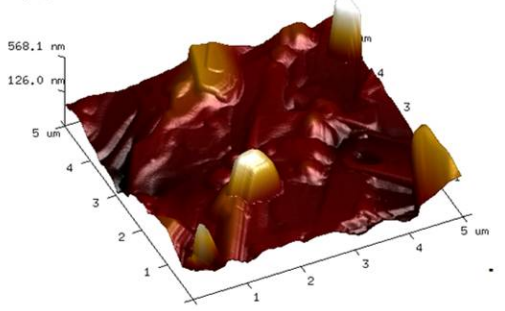

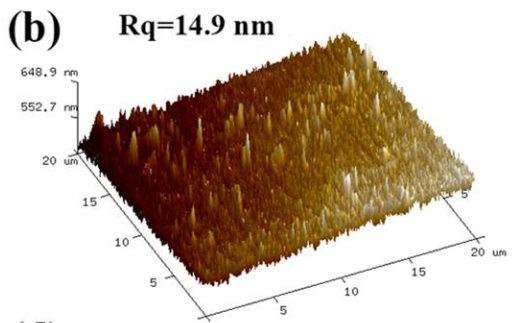

(d)

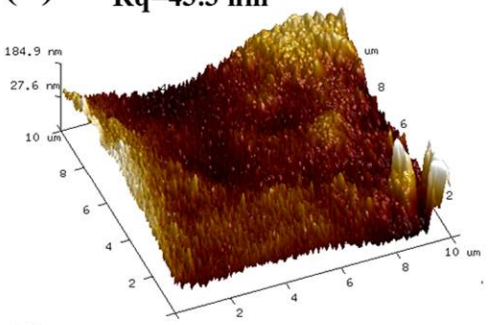

(f)

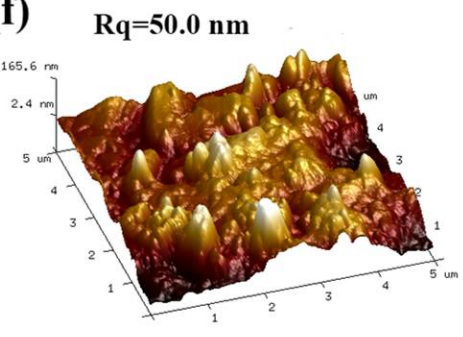

Figure 6. AFM images of different films before and after air plasma treatment. (a) PVA film; (b) PPVA-3 film; (c) CNC/PVA film; (d) CNC/PPVA-3 film; (e) CNC/OA/PVA film; (f) CNC/OA/PPVA-3 film.

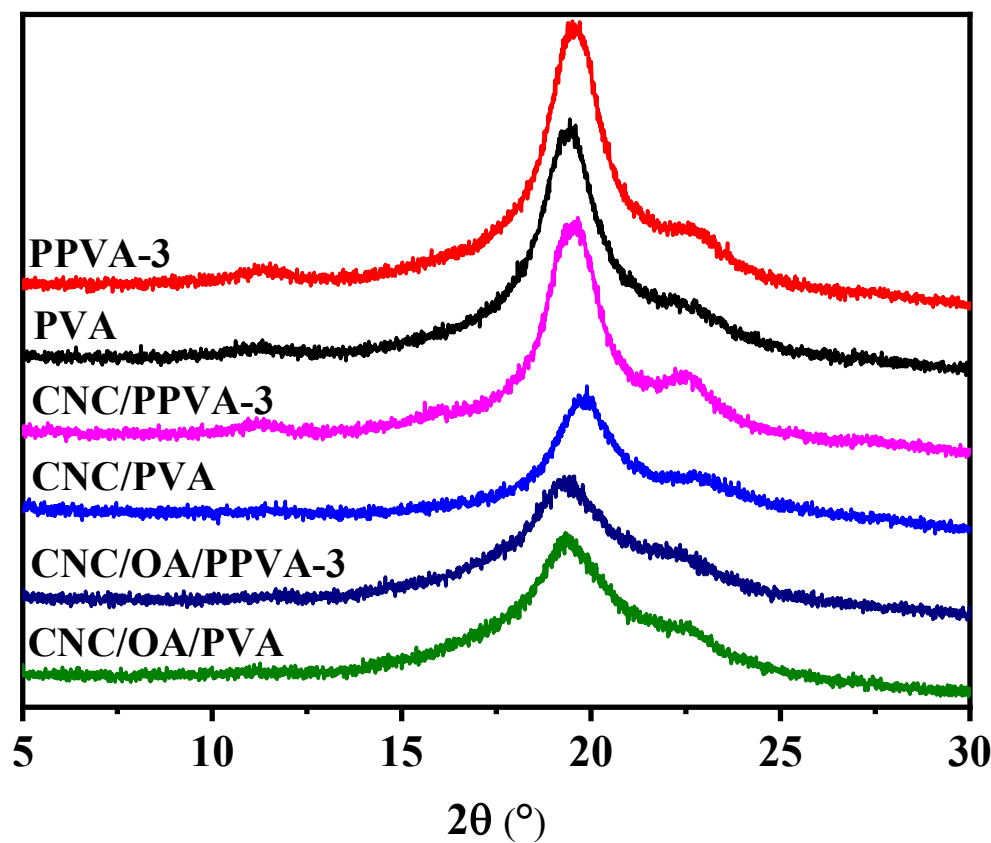

Figure 7. Effect of air plasma on X-ray diffraction patterns of different films before and after air plasma treatment. 


\subsection{Thermal Stability}

The effect of air plasma treatment on thermal stability of different films were evaluated by thermogravimetric analysis (Figure 8). As shown in Figure 8a, the weight loss occurred from $80^{\circ} \mathrm{C}$ to $160^{\circ} \mathrm{C}$ is due to the removal of free and bound moisture from samples. Later, two obvious weight-loss periods are observed for pure PVA film. The first period ranging from $190^{\circ} \mathrm{C}$ to $380^{\circ} \mathrm{C}$ is related to the dehydration of PVA sidechains and the second period ranging from $380^{\circ} \mathrm{C}$ to $500{ }^{\circ} \mathrm{C}$ is ascribed to the degradation of PVA backbones [39]. For all test films, the temperature at 10\% weight loss of each plasma-treated film is slightly higher than that of the corresponding untreated one (Table S1 in the Supplementary Materials). Furthermore, the onset temperature of decomposition $\left(\mathrm{T}_{\text {onset }}\right)$ and the temperature of maximum weight-loss rate $\left(\mathrm{T}_{\mathrm{DTG} \max }\right)$ of major weight-loss stages of air plasma-treated films are fairly close to those of untreated films (Figure 8b and Table S2). Despite this, it is evident to note that the PPVA-3 film loses weight more readily than pure PVA film in the temperature range from $260{ }^{\circ} \mathrm{C}$ to $320^{\circ} \mathrm{C}$ (Figure 8a,b). This is probably owing to the presence of partially cleaved $\mathrm{C}-\mathrm{C}$ bonds and newly formed oxygen-containing groups on the film surface after air plasma treatment. Although CNC/PPVA-3 film is more thermally stable than PPVA-3 owing to the reinforcement of $\mathrm{CNC}$, its weight-loss rate is still higher than that of $\mathrm{CNC} / \mathrm{PVA}$ from $272{ }^{\circ} \mathrm{C}$ to $342{ }^{\circ} \mathrm{C}$. It is interesting to note that the difference of thermal stability between CNC/OA/PVA and CNC/OA/PPVA-3 is negligible. In spite of the chemically modified surface by air plasma treatment, the inherent crosslinking network of ester bonds in CNC/OA/PVA film still takes a crucial role in keeping its relatively high thermal stability during thermogravimetric analysis. Besides, without the reinforcement of CNC (nano-filler) and/or crosslinking network, the residual mass ( $8.9 \%$ ) of PPVA-3 film is far less than that $(22.6 \%)$ of pure PVA film, while the residual weights of the other two plasma-treated films (namely, CNC/PPVA-3 and CNC/OA/PPVA-3) are in turn slightly higher than those of their respective untreated films (Table S1, Supplementary Materials).

(a)

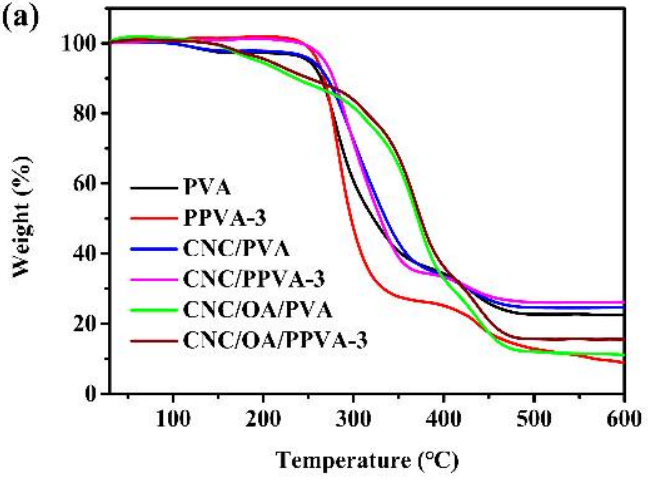

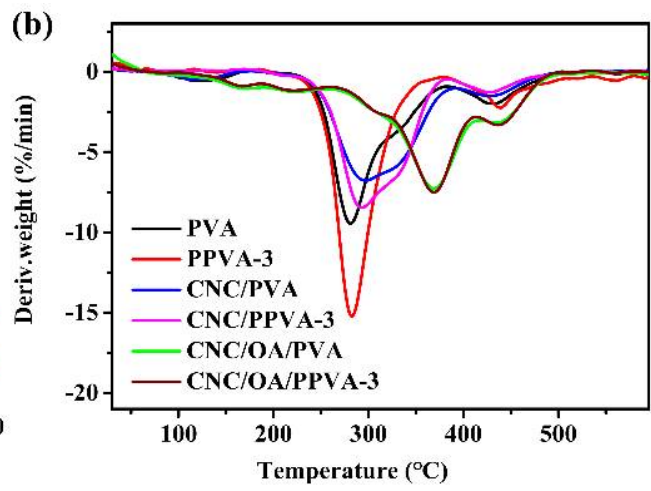

Figure 8. TGA (a) and DTG (b) thermographs of different films before and after air plasma trea-ment.

\section{Conclusions}

A green surface modification method by air plasma treatment was developed for preparation of a series of PVA-based films with remarkable water resistance and enhanced mechanical properties. After merely $3 \mathrm{~min}$ of air plasma irradiation, its modified product (CNC/OA/PPVA-3 film) possesses superior mechanical properties (tensile strength: $132.7 \mathrm{MPa}$; Young's modulus: $5379.9 \mathrm{MPa}$ ) and water resistance (degree of swelling: $47.5 \%$; solubility: $6.0 \%$ ). The air plasma treatment only changes the chemical structure of the film surface by increasing surface roughness and the amounts of oxygencontaining groups while leaving the internal structure intact. The hydrophobicity of the film surface could also be effectively increased by selecting proper treatment time but lengthy times of plasma etching should be avoided. Therefore, these air plasma treated PVA-based films could be applied as green packaging materials with enhanced water resistance and mechanical properties. 
Supplementary Materials: The following supporting information can be downloaded at: https: / / www.mdpi.com/article/10.3390/membranes12030249/s1, Figure S1: High resolution XPS spectra of O1s of different films without and with air plasma treatment; Table S1: The temperature at $10 \%$ weight loss and residual mass of different PVA-based films; Table S2: $\mathrm{T}_{\text {onset }}$ and $\mathrm{T}_{\mathrm{DTGmax}}$ values of major weight-loss stages of different PVA-based films; Figure S2: A possible reaction mechanism for air plasma treatment of CNC/OA/PVA film. The groups/linkages before and after air plasma treatment are marked with red-dashed circles and in red font color, respectively.

Author Contributions: Investigation, X.R., L.F. and Y.G.; data curation, X.R.; methodology, X.R., Q.Z. and Z.O.; software, Q.W.; writing-original draft, X.R.; writing-review and editing, X.D. and C.H.; supervision, X.D. and C.H.; funding acquisition, X.D. and C.H. All authors have read and agreed to the published version of the manuscript.

Funding: This research was funded by Hainan Provincial Natural Science Foundation (2019RC154 and 120RC456), National Natural Science Foundation of China (11805046), and the foundation of Guangxi Key Laboratory of Clean Pulp \& Papermaking and Pollution Control (2019KF26), College of Light Industry and Food Engineering, Guangxi University.

Data Availability Statement: Not applicable.

Acknowledgments: This work was supported by Hainan Provincial Natural Science Foundation (2019RC154 and 120RC456), National Natural Science Foundation of China (11805046), and the foundation (2019KF26) of Guangxi Key Laboratory of Clean Pulp \& Papermaking and Pollution Control, College of Light Industry and Food Engineering, Guangxi University.

Conflicts of Interest: The authors declare that they have no conflict of interest.

\section{References}

1. Yang, W.; Ding, H.; Qi, G.; Li, C.; Xu, P.; Zheng, T.; Zhu, X.; Kenny, J.M.; Puglia, D.; Ma, P. Highly transparent PVA/nanolignin composite films with excellent UV shielding, antibacterial and antioxidant performance. React. Funct. Polym. 2021, 162, 104873. [CrossRef]

2. Heydari, M.; Moheb, A.; Ghiaci, M.; Masoomi, M. Effect of cross-linking time on the thermal and mechanical properties and pervaporation performance of poly(vinyl alcohol) membrane cross-linked with fumaric acid used for dehydration of isopropanol. J. Appl. Polym. Sci. 2013, 128, 1640-1651. [CrossRef]

3. Shi, R.; Bi, J.; Zhang, Z.; Zhu, A.; Chen, D.; Zhou, X.; Zhang, L.; Tian, W. The effect of citric acid on the structural properties and cytotoxicity of the polyvinyl alcohol/starch films when molding at high temperature. Carbohydr. Polym. 2008, 74, 763-770. [CrossRef]

4. Popescu, M.-C. Structure and sorption properties of CNC reinforced PVA films. Int. J. Biol. Macromol. 2017, 101, 783-790. [CrossRef]

5. Tian, H.; Yan, J.; Rajulu, A.V.; Xiang, A.; Luo, X. Fabrication and properties of polyvinyl alcohol/starch blend films: Effect of composition and humidity. Int. J. Biol. Macromol. 2017, 96, 518-523. [CrossRef]

6. Zhang, Q.; Chen, D. Enhanced Mechanical Properties of Graphene-Based Poly(vinyl alcohol) Composites. Macromolecules 2010, 43, 2357-2363.

7. Bonilla, J.; Fortunati, E.; Atarés, L.; Chiralt, A.; Kenny, J.M. Physical, structural and antimicrobial properties of poly vinyl alcohol-chitosan biodegradable films. Food Hydrocoll. 2014, 35, 463-470. [CrossRef]

8. Chowdhury, S.; Teoh, Y.; Ong, K.; Zaidi, N.; Mah, S.-K. Poly(vinyl) alcohol crosslinked composite packaging film containing gold nanoparticles on shelf life extension of banana. Food Packag. Shelf Life 2020, 24, 100463. [CrossRef]

9. Yang, W.; Qi, G.; Kenny, J.; Puglia, D.; Ma, P. Effect of Cellulose Nanocrystals and Lignin Nanoparticles on Mechanical, Antioxidant and Water Vapour Barrier Properties of Glutaraldehyde Crosslinked PVA Films. Polymers 2020, 12, 1364. [CrossRef]

10. He, Z.; Jiang, S.; Li, Q.; Wang, J.; Zhao, Y.; Kang, M. Facile and cost-effective synthesis of isocyanate microcapsules via polyvinyl alcohol-mediated interfacial polymerization and their application in self-healing materials. Compos. Sci. Technol. 2017, 138, 15-23. [CrossRef]

11. Sonker, A.K.; Tiwari, N.; Nagarale, R.K.; Verma, V. Synergistic effect of cellulose nanowhiskers reinforcement and dicarboxylic acids crosslinking towards polyvinyl alcohol properties. J. Polym. Sci. Part A Polym. Chem. 2016, 54, 2515-2525. [CrossRef]

12. Suganthi, S.; Vignesh, S.; Kalyana Sundar, J.; Raj, V. Fabrication of PVA polymer films with improved antibacterial activity by fine-tuning via organic acids for food packaging applications. Appl. Water Sci. 2020, 10, 100. [CrossRef]

13. Bozdogan, A.; Aksakal, B.; Denktaş, C.; Salt, Y. Prestretching effect and recovery process of polyvinyl alcohol film crosslinked with tartaric acid. J. Appl. Polym. Sci. 2020, 137, 49421. [CrossRef]

14. Cornelius, C.; McCord, M.; Bourham, M.; Hauser, P. Desizing of PVA sized pet/cotton fabrics with atmospheric pressure plasma. Cellulose 2018, 25, 869-881. [CrossRef] 
15. Arik, N.; Inan, A.; Ibis, F.; Demirci, E.A.; Karaman, O.; Ercan, U.; Horzum, N. Modification of electrospun PVA/PAA scaffolds by cold atmospheric plasma: Alignment, antibacterial activity, and biocompatibility. Polym. Bull. 2019, 76, 797-812. [CrossRef]

16. Premkumar, P.S. Preparation and electrical studies on pure and oxygen plasma treated polyvinyl alcohol films. J. Mater. Res. Technol. 2019, 8, 2232-2237. [CrossRef]

17. Paneru, R.; Ki, S.H.; Lamichhane, P.; Nguyen, L.; Adhikari, B.; Jeong, I.; Mumtaz, S.; Choi, J.; Kwon, J.-S.; Choi, E. Enhancement of antibacterial and wettability performances of polyvinyl alcohol/chitosan film using non-thermal atmospheric pressure plasma. Appl. Surf. Sci. 2020, 532, 147339. [CrossRef]

18. Ojah, N.; Saikia, D.; Gogoi, D.; Baishya, P.; Ahmed, G.A.; Ramteke, A.; Choudhury, A.J. Surface modification of core-shell silk/PVA nanofibers by oxygen dielectric barrier discharge plasma: Studies of physico-chemical properties and drug release behavior. Appl. Surf. Sci. 2019, 475, 219-229. [CrossRef]

19. Dalei, G.; Das, S.; Jena, S.; Nayak, J.; Samanta, L.; Das, S. Surface modification of cellulose/polyvinyl alcohol biocomposites by non-thermal argon plasma: Applications towards biological relevance. Cellulose 2019, 26, 2437-2451. [CrossRef]

20. Yang, S.-Y.; Huang, C.-Y. Plasma treatment for enhancing mechanical and thermal properties of biodegradable PVA/starch blends. J. Appl. Polym. Sci. 2008, 109, 2452-2459. [CrossRef]

21. Guo, Z.; Gou, Q.; Yang, L.; Yu, Q.-L.; Han, L. Dielectric barrier discharge plasma: A green method to change structure of potato starch and improve physicochemical properties of potato starch films. Food Chem. 2022, 370, 130992. [CrossRef]

22. Swaraj, S.; Oran, U.; Lippitz, A.; Friedrich, J.F.; Unger, W.E.S. Surface Analysis of Plasma-Deposited Polymer Films, 6. Plasma Processes Polym. 2005, 2, 572-580. [CrossRef]

23. Perez, P.; Flores, P.; Velazquez, G.; Sanchez, E.; Fernandez, O.; Hernández, E.; Mendez-Montealvo, G.; Sifuentes-Nieves, I Rheological performance of film-forming solutions made from plasma-modified starches with different amylose/amylopectin content. Carbohydr. Polym. 2021, 255, 117349. [CrossRef]

24. Goiana, M.; Brito, E.; Alves Filho, E.; Miguel, E.; Fernandes, F.; Azeredo, H.; Rosa, M. Corn starch based films treated by dielectric barrier discharge plasma. Int. J. Biol. Macromol. 2021, 183, 2009-2016. [CrossRef]

25. Suzuki, M.; Kishida, A.; Iwata, H.; Ikada, Y. Graft copolymerization of acrylamide onto a polyethylene surface pretreated with glow discharge. Macromolecules 1986, 19, 1804-1808. [CrossRef]

26. Sifuentes-Nieves, I.; Flores-Silva, P.C.; Gallardo-Vega, C.; Hernández-Hernández, E.; Neira-Velázquez, G.; Mendez-Montealvo, G.; Velazquez, G. Films made from plasma-modified corn starch: Chemical, mechanical and barrier properties. Carbohydr. Polym. 2020, 237, 116103. [CrossRef]

27. Kousal, J.; Krtouš, Z.; Kolářová Rašková, Z.; Sedlaříková, J.; Schäfer, J.; Kučerová, L.; Shelemin, A.; Solař, P.; Hurajová, A.; Biederman, H.; et al. Degradable plasma polymer films with tailored hydrolysis behavior. Vacuum 2020, 173, 109062. [CrossRef]

28. Matouk, Z.; Torriss, B.; Rincón, R.; Dorris, A.; Beck, S.; Berry, R.M.; Chaker, M. Functionalization of cellulose nanocrystal films using Non-Thermal atmospheric -Pressure plasmas. Appl. Surf. Sci. 2020, 511, 145566. [CrossRef]

29. Oh, Y.A.; Roh, S.H.; Min, S.C. Cold plasma treatments for improvement of the applicability of defatted soybean meal-based edible film in food packaging. Food Hydrocoll. 2016, 58, 150-159. [CrossRef]

30. Fu, Q.; Jin, Y.; Song, X.; Gao, J.; Han, X.; Jiang, X.; Zhao, Q.; Yu, D. Size-dependent mechanical properties of PVA nanofibers reduced via air plasma treatment. Nanotechnology 2010, 21, 095703. [CrossRef]

31. Czylkowski, D.; Hrycak, B.; Sikora, A.; Moczała-Dusanowska, M.; Dors, M.; Jasiński, M. Surface Modification of Polycarbonate by an Atmospheric Pressure Argon Microwave Plasma Sheet. Materials 2019, 12, 2418. [CrossRef] [PubMed]

32. Cai, Z.; Qiu, Y. The mechanism of air/oxygen/helium atmospheric plasma action on PVA. J. Appl. Polym. Sci. 2006, 99, 2233-2237. [CrossRef]

33. Moosavi, M.H.; Khani, M.R.; Shokri, B.; Hosseini, S.M.; Shojaee-Aliabadi, S.; Mirmoghtadaie, L. Modifications of protein-based films using cold plasma. Int. J. Biol. Macromol. 2020, 142, 769-777. [CrossRef] [PubMed]

34. Das, P.; Ojah, N.; Kandimalla, R.; Mohan, K.; Gogoi, D.; Dolui, S.K.; Choudhury, A.J. Surface modification of electrospun PVA/chitosan nanofibers by dielectric barrier discharge plasma at atmospheric pressure and studies of their mechanical properties and biocompatibility. Int. J. Biol. Macromol. 2018, 114, 1026-1032. [CrossRef] [PubMed]

35. Carbone, E.A.D.; Boucher, N.; Sferrazza, M.; Reniers, F. How to increase the hydrophobicity of PTFE surfaces using an r.f. atmospheric-pressure plasma torch. Surf. Interface Anal. 2010, 42, 1014-1018. [CrossRef]

36. Bahrami, R.; Zibaei, R.; Hashami, Z.; Hasanvand, S.; Garavand, F.; Rouhi, M.; Jafari, S.; Mohammadi, R. Modification and improvement of biodegradable packaging films by cold plasma; a critical review. Crit. Rev. Food Sci. Nutr. 2020, 1-15. [CrossRef] [PubMed]

37. Lu, J.; Wang, T.; Drzal, L. Preparation and properties of microfibrillated cellulose polyvinyl alcohol composite materials. Compos. Part A 2008, 39, 738-746. [CrossRef]

38. Lim, M.; Kwon, H.; Kim, D.; Seo, J.; Han, H.; Khan, S.B. Highly-enhanced water resistant and oxygen barrier properties of cross-linked poly(vinyl alcohol) hybrid films for packaging applications. Prog. Org. Coat. 2015, 85, 68-75. [CrossRef]

39. Wu, J.; Du, X.; Yin, Z.; Xu, S.; Xu, S.; Zhang, Y. Preparation and characterization of cellulose nanofibrils from coconut coir fibers and their reinforcements in biodegradable composite films. Carbohydr. Polym. 2019, 211, 49-56. [CrossRef] 